\title{
Slavische Mikroliteratursprachen - Zur Applizierbarkeit eines Paradigmas im westslavischen Sprachraum
}

\section{Slavic Literary Microlanguages-Paradigm Applicability in the West Slavic Language Area}

Martin Henzelmann

(Hamburg, Deutschland)

\begin{abstract}
:
In this paper, I will be taking a closer look at the term Slavic literary microlanguage and trying to explain it in the context of several West-Slavic case studies. I will present six West-Slavic language varieties, which are currently classified as Slavic literary microlanguages. These linguistic varieties are characterized by some common features, for example, concerning the number of speakers or their restriction to regional use. Furthermore, I will examine their classification and I will discuss to what extent the theory of Slavic literary microlanguages is applicable in the West Slavic language area.
\end{abstract}

\section{Key words:}

West Slavic Literary Microlanguages; Lower Sorbian; Upper Sorbian; Kashubian; Upper Silesian; Lachian; Eastern Slovak

\section{Zusammenfassung:}

Im vorliegenden Beitrag werden westslavische Varietäten vorgestellt, welche gegenwärtig im Kanon der slavischen Mikroliteratursprachen auftreten. ${ }^{1}$ Es soll hinterfragt werden, durch welche Umstände diese Zuordnung motiviert ist und welche Grenzen ihr die Praxis aufzeigt. Der Status dieser Varietäten wird vor dem Hintergrund gegenwärtiger Tendenzen und sprachlicher Aktivitäten umrissen, so dass sich neue

1 Ich bedanke mich herzlich bei zwei anonymen Rezensenten für ihre wertvollen Anmerkungen. 
Ansätze zur grundlegenden theoretischen Verortung von Mikroliteratursprachen im westslavischen Kontinuum bieten.

\section{Schlüsselbegriffe :}

Westslavische Mikroliteratursprachen; Niedersorbisch; Obersorbisch; Kaschubisch; Oberschlesisch; Lachisch; Ostslowakisch

Die bibliographischen Angaben zu kyrillisch geschriebenen Quelltexten werden im vorliegenden Beitrag nach der redaktionellen Norm der Zeitschrift Opera Slavica und in Übereinstimmung mit der Empfehlung zur latinisierten Wiedergabe nicht in lateinischer Ausgangsschrift verfasster Texte transliteriert, welche von der Tschechischen Nationalbibliothek vorgegeben ist.

\section{Zum Begriffsapparat einer slavischen Mikroliteratursprache}

In der slavistischen Sprachwissenschaft hat sich der Begriff „Mikroliteratursprache“ etabliert, der in erster Linie auf die Arbeiten von Aleksandr D. Duličenko zurückgeht. In seiner Monographie aus dem Jahre 1981, die bis heute als wegweisende Orientiereng in der Forschung verstanden wird, spricht er sich für eine Kanonisierung des terminologischen Bedeutungsumfangs aus. Er dokumentiert seine Ansätze, welche sich vor allem auf die Entdeckung der Zeitschrift Ruske Slovo bei den Russinen in der Vojvodina zurückführen und durch die Erforschung ihrer sprachlichen Besonderheiten erklären lassen. ${ }^{2}$ In diesem Zusammenhang wird eine terminologische Definition vorgeschlagen, die sich aus unterschiedlichen Argumenten konstituiert, von denen jedoch eine Aussage ganz besonders heraussticht:

Что понимается нами под термином литературный микроязык? Сразу же хотелось бы обратить внимание на то, что появление на том или ином говоре или диалекте, не ставших базой того или иного литературного языка, отдельных сборников поэзии или прозы или же текстов других жанров еще не говорит о начале литературного языка. Контуры ЛМЯа вырисовываются лишь тогда, когда единичные акты рассматриваемого характера постепенно превращаются в процесс, который мы называем литературно-языковым, т.е. это организованный процесс, в конечном счете приводящий к созданию литературного языка. ${ }^{3}$

2 DULIČENKO, A. D.: Slavjanskije literaturnyje mikrojazyki. Voprosy formirovanija i razvitija. Tallin: Valgus, 1981.

3 DULIČENKO, A. D.: Sovremennoje jazykoznanije i slavjanskije literaturnyje mikrojazyki. In: DULIČENKO, A. D. - GUSTAVSSON, S. (eds): Slavjanskije literaturnyje mikrojazyki i jazykovyje kontakty: Materialy meždunarodnoj konferencii, organizovannoj v ramkach Komissii po jazykovym 
Duličenko geht also davon aus, dass ein organisierter Prozess erkennbar sein muss, welcher es ermöglicht, einem Idiom den Status als Mikroliteratursprache zuzuerkennen. ${ }^{4}$ Die Sprachen, die dieses Kriterium für ihn in unterschiedlicher Intensität erfüllen, werden in vier größere Gruppen nach einem areal-geographischen Prinzip eingeteilt, von denen die erste Gruppe durch autonome Mikroliteratursprachen vertreten wird. Diese Zuordnung erfordert eine weitreichende geographische und ethnolinguistische Unabhängigkeit der jeweiligen Sprachformen in zahlreichen Domänen, weshalb sie in ihrer Beschaffenheit nahe an ausgebaute Standardsprachen mit eingeschränkten Möglichkeiten heranrücken. Sie sind in ihrer Funktionalität vergleichsweise weit vorangeschritten. Auch die zweite Gruppe, nämlich die der Mikroliteratursprachen in Insellage, wird als relativ gut entwickelt und ausbaufähig betrachtet. Sie kennzeichnet sich dadurch, dass die zu ihr gehörenden Varietäten vom sprachlichen und ethnischen Ursprung ihrer nahestehenden Standardsprache isoliert sind und vollständig in fremdsprachiger Umgebung liegen. Die dritte Gruppe bilden Mikroliteratursprachen in peripherer Insellage, welche zwar in fremdsprachiger Umgebung sind und durch eine Staatsgrenze von ihrer nahestehenden Varietät getrennt werden, aber dennoch zu dieser nahestehenden Varietät enge Beziehungen aufweisen. Ihnen werden Anzeichen für einen normativen Ausbau attestiert. Die letzte und am wenigsten ausgebaute Gruppe stellen periphere Mikroliteratursprachen dar, welche innerhalb eines Staates in unmittelbarer Nachbarschaft zu ihrer genetisch nahestehenden Sprache liegen. ${ }^{5}$

kontaktam pri Meždunarodnom Komitete slavistov. Tartu, 15-17 sentjabrja $2005 \mathrm{~g}$. Slavica Tartuensia, VII. Tartu: Tartu Ülikooli Kirjastus, 2006, S. 26-27, s. auch DULIČENKO, A. D.: Sovremennaja ètnojazykovaja mikroslavija: sostojanije i perspektivy razvitija. In: PLJIŠKOVA, A. (ed.): Rusyn'skỳj jazỳk medžì dvoma kongresamy. Zbornyk referativ z III. Medžìnarodnoho kongresu rusyn'skoho jazỳka, Krakìv, 13.-16. 9. 2007. Prjašìv: Svìtovỳj kongres Rusynìv. İnštitut rusyn'skoho jazỳka ì kulturỳ Prjašivskoj unìverzìtỳ v Prjašovì, 2008, S. 38 und DULIČENKO, A. D.: Osnovy slavjanskoj filologii. Lingvističeskaja problematika. Vol. 2. Opole: Uniwersytet Opolski - Instytut Filologii Polskiej. Opolskie Towarzystwo Przyjaciół Nauk, 2011, S. 319.

4 Zur Diskussion um die Verwendung des Begriffsapparats vgl. HENZELMANN, M.: Authentizität als treibende Kraft bei der Herausbildung slavischer Mikroliteratursprachen (am Beispiel des Pomakischen und des Schlesischen). Specimina Philologiae Slavicae, 185. München et al.: Verlag Otto Sagner, 2015, S. 13-64. Dort wird für eine genaue und vor allem praxisorientierte Überprüfung des organisierten Prozesses plädiert, die in erster Linie darauf abzielen soll, die Bedürfnisse einer Sprechergemeinschaft abzubilden. Daher wird ebd. vorgeschlagen, Authentizität als wesentlichen Aspekt bei der Herausbildung slavischer Mikroliteratursprachen zu definieren. Ein Prozess kann noch so gut organisiert sein, er wird trotzdem sein Ziel verfehlen, wenn die Sprachträger sich seinen Inhalten verweigern, s. dazu auch bei David Crystal, der schreibt: „Not only must the work be 'on a language, for its speakers and with its speakers', it also needs to be 'by its speakers'" (CRYSTAL, D.: Language Death. Cambridge: Cambridge University Press, 2000, S. 157).

5 Dargestellt nach DULIČENKO,A.D.: Sovremennoje jazykoznanije i slavjanskije literaturnyje mikrojazyki. In: DULIČENKO, A. D. - GUSTAVSSON, S. (eds): Slavjanskije literaturnyje mikrojazyki i jazykovyje kontakty: Materialy meždunarodnoj konferencii, organizovannoj v ramkach Komissii 
Dass diese Klassifikation nicht willkürlich ist, sondern sich auf unterschiedliche soziodynamische Tendenzen stützt, zeigt das Plädoyer Duličenkos für die Berücksichtigung unterschiedlicher Faktoren. Diese geben ihrerseits Aufschluss über die Umstände, unter denen eine Herausbildung literatursprachlicher Normen im kleinen Maßstab möglich wird. ${ }^{6}$ Demnach handelt es sich um Sprachen ähnlich den Standardsprachen, jedoch in einem deutlich kleineren Rahmen. Von Dialekten unterscheiden sie sich durch ihre Kodifikationsansätze und durch eine Textproduktion auf multiplen Ebenen. Die Herausgabe von Textdokumenten fundiert auf einem bestimmten Dialekt, weiterhin werden normative Prozesse eingeleitet, die zur inneren Stabilisierung und zur Straffung der Funktionalität beitragen. Im Ergebnis können Lehrwerke, Regelwerke und Wörterbücher entstehen, die wiederum als Grundlage für eine Erweiterung des Radius in der Schriftlichkeit dienen. Es werden zudem die unterschiedlichen funktionalen Anwendungsbereiche analysiert, bevor abschließend herausgestellt wird, dass ein gesellschaftlich organsierter und akzeptierter Prozess regulierend wirkt, und um zu überprüfen, welche Anwendungsbereiche von einer Mikroliteratursprache bedient werden, erstellt Duličenko eine Tabelle, in der funktionale Teilaspekte der jeweiligen Sprache aufgelistet werden. Das Vorhandensein eines bestimmten Merkmals wird mit einem Pluszeichen, ein eingeschränkt auftretendes Kriterium mit einem eingeklammerten Zeichen, die Abwesenheit mit einem Minus und eine mangelnde Datengrundlage mit einem freigelassenen Feld gekennzeichnet, aber auch Fragezeichen werden eingearbeitet, ihre Funktion wird nicht näher erläutert. Eine aktuelle Version dieser Tabelle beinhaltet folgende Kriterien: ${ }^{7}$

- Literatur (Lyrik, Kurzgeschichten, Novellen)

- Massenmedien (Zeitungen, Zeitschriften, Jahrbücher, gemischte Ausgaben, Radio und Fernsehen)

- Bildungswesen (Grundschule, Mittelstufe, Gymnasium, Klassen mit allen oder einigen Fächern, Hochschulausbildung)

- Verwaltung

- Wissenschaft

- Religion (Verwendung der Sprachform in der Kirche und Bibelübersetzungen)

po jazykovym kontaktam pri Meždunarodnom Komitete slavistov. Tartu, 15-17 sentjabrja $2005 \mathrm{~g}$. Slavica Tartuensia, VII. Tartu: Tartu Ülikooli Kirjastus, 2006, S. 29-33.

6 Zit. nach DULIČENKO, A. D.: Osnovy slavjanskoj filologii. Lingvističeskaja problematika. Vol. 2. Opole: Uniwersytet Opolski - Instytut Filologii Polskiej. Opolskie Towarzystwo Przyjaciół Nauk, 2011, S. 318-319 und DULIČENKO, A. D.: Vvedenije v slavjanskuju filologiju. Učebnoje posobije. Moskva: Flinta-Nauka, 2016, s. 573-574.

7 DULIČENKO, A. D.: Osnovy slavjanskoj filologii. Lingvističeskaja problematika. Vol. 2. Opole: Uniwersytet Opolski - Instytut Filologii Polskiej. Opolskie Towarzystwo Przyjaciół Nauk, 2011, S. 343 bzw. DULIČENKO, A. D.: Vvedenije v slavjanskuju filologiju. Učebnoje posobije. Moskva: Flinta-Nauka, 2016, S. 600-601. 
- Institutionen

- Theater

- topographische Aufschriften

- persönliche Korrespondenz

Die hier dargestellten Eckpfeiler gelten als richtungsweisend für Duličenko und werden exemplarisch an Hand von Tabellen abgeglichen, in kürzeren Paragraphen dokumentiert und teilweise erläutert. Alle oben erwähnten Merkmale spielen gleichermaßen eine Rolle und können von Fall zu Fall in unterschiedlicher Intensität beobachtet werden. Interessant ist dabei eine genauere Betrachtung der Varietäten, die für den westslavischen Sprachraum als Mikroliteratursprachen ${ }^{8}$ postuliert werden.

\section{Die aktuelle Klassifikation westslavischer Mikroliteratursprachen}

Vor dem Hintergrund dieser allgemeinen Ansichten klassifiziert Duličenko einige westslavische Mikroliteratursprachen, deren Zuordnung jedoch im Laufe der Zeit schwankt. In den Kanon der slavischen Mikroliteratursprachen werden die sechs folgenden sprachlichen Phänomene aufgenommen.

\section{Niedersorbisch}

Das Niedersorbische (nds. dolnoserbšćina) ${ }^{9}$ erfährt in ${ }_{51}$ Städten und Gemeinden im deutschen Bundesland Brandenburg eine offizielle Anerkennung, wenngleich diese Zahl variabel ist und sich somit in Zukunft ändern könnte. ${ }^{10}$ Aus einer soziolinguistischen Studie, die Mitte der 1990er Jahre durchgeführt wurde geht hervor, dass maximal 7.00o Sprecher im Siedlungsgebiet leben, ${ }^{11}$ was bereits eine optimistische Schätzung ist, denn es darf als wahrscheinlich gelten, dass hier auch

8 Auf einen historischen Abriss der jeweiligen Varietäten wird hier aus Platzgründen weitestgehend verzichtet, stattdessen verweise ich jeweils auf andere Quellen, die darüber eine fundierte Aussage treffen. Wichtig ist an dieser Stelle vor allem das Vorhandensein von Schriftlichkeit, welches für die zu untersuchenden Phänomene auch in unterschiedlicher Intensität und zu unterschiedlichen Zeitpunkten vorhanden war bzw. ist und Duličenko als Klassifikationsgrundlage dient.

9 Der intensive Ausbau des Niedersorbischen lässt sich im 16. Jahrhundert erkennen und führt zur Übersetzung religiöser Texte, und dies nicht nur mit dem Zweck einer Erweiterung bereits vorhandener kirchlicher Terminologie. Nach schwankenden Entwicklungstendenzen ist es vor allem die erste Hälfte des 20. Jahrhunderts, die die Sprecherzahlen rapide sinken lässt (SPIESS, G.: Niedersorbisch. In: OKUKA, M. (ed.): Wieser Enzyklopädie des Europäischen Ostens, 10: Lexikon der Sprachen des Europäischen Ostens. Klagenfurt: Wieser, 2002, S. 337-338).

10 Ibidem, S. 323.

11 Ibidem, S. 324. 
Personen berücksichtigt wurden, die das Niedersorbische nur auf minimalem Niveau beherrschen. ${ }^{12}$

Im Hinblick auf ihre Klassifikation ist festzuhalten, dass die Sprache zunächst nicht in den Kanon der Mikroliteratursprachen aufgenommen wird, da Duličenko davon ausgeht, dass sich die Sprechergruppe in ihren Konturen so stark verfestigt habe, dass sie eher mit einer großen Nation zu vergleichen sei, weshalb er sie auch zunächst außen vor lässt. ${ }^{13}$ Später erfolgt ein Paradigmenwechsel und es wird herausgestellt, dass es doch sinnvoll sei, das Niedersorbische als slavische Mikroliteratursprache zu bezeichnen. So finden wir insbesondere in den späteren Werken grundsätzliche Angaben über die Beschaffenheit des Niedersorbischen, zudem wird die Sprache in die Gruppe der autonomen Mikroliteratursprachen eingereiht. ${ }^{14}$ Dieser Punkt ist diachron denkbar und macht durchaus Sinn im Hinblick auf die eigenständige Entwicklung des Niedersorbischen, ${ }^{15}$ allerdings spricht Achim Rabus davon, dass die Sprache in ihrer heutigen Form kaum noch als autonom betrachtet werden kann. ${ }^{16}$ Dies hängt sicher mit den Tatsachen zusammen, die in Tadeusz Lewaszkiewiczs düsterer Perspektive unter dem Postulat eines schleichenden Sprachtods summiert werden, ${ }^{17}$ so dass hier bereits zu überprüfen wäre, in welche Kategorie sich das Niedersorbische aus synchroner Perspektive einordnen ließe. ${ }^{18}$ In Bezug auf die Publikationstätigkeit stellt Duličenko heraus, dass bereits ab dem Jahre 1650 eine eigenständige Kodifikation zu beobachten sei,${ }^{19}$ in der Tabelle aus

12 LEWASZKIEWICZ, T.: Dolnotużycki i górnotużycki - języki zagrożone czy wymierające? Slavia Occidentalis, 2014, 71/1, S. 43.

13 DULIČENKO, A. D.: Slavjanskije literaturnyje mikrojazyki. Voprosy formirovanija i razvitija. Tallin: Valgus, 1981, S. 16.

14 DULIČENKO, A. D.: Slavjanskaja mikrolingvistika i slavjanskaja mikrofilologija. Balkanistic Forum, 2017, 3, S. 12; DULIČENKO, A. D.: Slavjanskaja mikrofilologija. In: DULIČENKO, A. D. NOMATI, M. (eds): Slavjanskaja mikrofilologija. Slavica Tartuensia, XI - Slavic Eurasian Studies, 34. Tartu-Sapporo: Tartu Ülikooli Kirjastus - Hokkaido University Press, 2018, S. 4.

15 MARTI, R.: Haut- et bas-sorabe: une cohabitation linguistique difficile. Revue des études slaves, 2014, LXXXV-2, S. 217-226.

16 RABUS, A.: Slavische Minderheitensprachen - Mikrostandardsprachen? Zeitschrift für Slavische Philologie, 2015, 71/1, S. 150.

17 Er schreibt: „Sytuację dolnołużyckiego można określić jako stan powolnej agonii językowej“. LEWASZKIEWICZ, T.: Dolnołużycki i górnotużycki - języki zagrożone czy wymierające? Slavia Occidentalis, 2014, 71/1, S. 48.

18 Das Kernproblem, das wir bei Roland Marti erklärt finden, ist bezeichnend für das Ausschleichen einer Sprache: „En Basse-Lusace, la transmission de la langue dans la famille a cessé, et ceux qui parlent le sorabe comme langue maternelle ont plus de 60 ans". MARTI, R.: Haut- et bas-sorabe: une cohabitation linguistique difficile. Revue des études slaves, 2014, LXXXV-2, S. 216.

19 DULIČENKO, A. D.: Slavjanskaja mikrolingvistika i slavjanskaja mikrofilologija. Balkanistic Forum, 2017, 3, S. 12; DULIČENKO, A. D.: Slavjanskaja mikrofilologija. In: DULIČENKO, A. D. - 
früheren Beiträgen wird schließlich ersichtlich, wie sich diese Tätigkeiten gestalten: ${ }^{20}$ Während etwa das Vorhandensein von Lyrik, Zeitungen oder Jahreszeitschriften konstatiert wird, so bleiben die Spalten für Romane oder Fernsehsendungen frei, bei den topographischen Aufschriften steht sogar ein Fragezeichen, obwohl diese dem Reisenden vor Ort zuallererst auffallen, markieren sie doch einen wesentlichen Unterschied zur ansonsten weitestgehend monolingual beschilderten Landschaft des Bundeslandes Brandenburg. ${ }^{21}$ Was das Niedersorbische heute vor allem für die Kanonisierung slavischer Mikroliteratursprachen interessant macht sind die nachhaltigen Revitalisierungsversuche, die etwa im Zuge des Witaj-Projekts ${ }^{22}$ unternommen werden, um der voranschreitenden Attrition entgegenzuwirken. Es geht insbesondere darum zu vermeiden, dass die Sprache ihrem Schicksal überlassen und sich noch mehr dem Druck des Deutschen beugen wird, und dass möglichst viele Bereiche kultiviert werden, in denen das Niedersorbische auch tatsächlich gesprochen wird. ${ }^{23}$ So existiert heute ein weiträumiges Arbeitsangebot von der Kita an über zahlreiche Bildungsstufen hinweg in niedersorbischer Sprache, so dass gegenwärtig beispielsweise rund 1.300 Schüler von den vorhandenen Bildungsmöglichkeiten profitieren. ${ }^{24}$

NOMATI, M. (eds): Slavjanskaja mikrofilologija. Slavica Tartuensia, XI - Slavic Eurasian Studies, 34. Tartu-Sapporo: Tartu Ülikooli Kirjastus - Hokkaido University Press, 2018, S. 4.

20 DULIČENKO, A. D.: Sovremennoje jazykoznanije i slavjanskije literaturnyje mikrojazyki. In: DULIČENKO, A. D. - GUSTAVSSON, S. (eds): Slavjanskije literaturnyje mikrojazyki i jazykovyje kontakty: Materialy meždunarodnoj konferencii, organizovannoj v ramkach Komissii po jazykovym kontaktam pri Meždunarodnom Komitete slavistov. Tartu, 15-17 sentjabrja 2005 g. Slavica Tartuensia, VII. Tartu: Tartu Ülikooli Kirjastus, 2006, S. 42; DULIČENKO, A. D.: Vvedenije v slavjanskuju filologiju. Učebnoje posobije. Moskva: Flinta-Nauka, 2016, S. 600-601.

21 Die Verwendung des Niedersorbischen im angestammten Gebiet der Gruppe ist durch die Verfassung des Landes Brandenburg gedeckt, weshalb eine juristische Absicherung für die Sprache gegeben ist. Dies gilt auch für das Einbeziehen der Sprache in den öffentlichen Raum (s. dazu VERFASSUNG DES LANDES BRANDENBURG: <https://bravors.brandenburg.de/de/gesetze-212792\#25>. [online]. [cit. 3. 11. 2018]).

22 Das Witaj-Projekt startete 1998 mit dem Ziel, die Sprache und Kultur der Sorben in der gesamten Lausitz zu unterstützen und wird bis heute mit Hilfe der Immersionsmethode umgesetzt. Bereits vom Kindergarten an bis über die Schulbildung wird das Konzept eines intensiven Kontakts zur jeweiligen sorbischen Sprache angeboten (aktuelle Ergebnisse und Perspektiven umfassend dokumentiert bei SCHULZ, J.: Bilingualer Spracherwerb im Witaj-Projekt. Schriften des Sorbischen Instituts. Spisy Serbskeho instituta, 60. Bautzen-Budyšin: Domowina, 2015).

23 Roland Marti geht daher davon aus, dass „les activités de ces dernières années visent au maintien de la langue là où elle est encore parlée et à la revitalisation dans les régions et auprès des personnes germanisées“. MARTI, R.: Haut- et bas-sorabe: une cohabitation linguistique difficile. Revue des études slaves, 2014, LXXXV-2, S. 216.

24 NOWAK, M.: Sorben/Wenden und die Sprache Niedersorbisch - Ein Thema für den Deutschunterricht? In: BERNER, E. (ed.): Region-Sprache-Literatur. Unterrichtsanregungen und Materialien für den Deutschunterricht in der Primar- und Sekundarstufe. Potsdam: Universitätsverlag, 2017, S. 165. 
Der Terminus Mikroliteratursprache erfährt letztlich seine Berechtigung für die Klassifikation des Niedersorbischen, da es sich um die zahlenmäßig kleinste noch gesprochene slavische Sprache überhaupt handelt und somit ein numerischer Aspekt den geographischen ergänzt. Der von Duličenko eingeforderte organisierte Prozess des Sprachausbaus lässt sich gleichermaßen für einen Spracherhalt postulieren, denn heute wirkt man soziodynamischen Ungleichheiten im Hinblick auf Sprachverwendungsattitüden entgegen. Dies kann jedoch - so Lewaszkiewiczs These - nur dann zielführend sein, wenn die Gruppe selbst ein Interesse daran zeigt, das Prestige der Varietät aufzuwerten, sie wieder in der Kommunikation mit Familienmitgliedern zu verwenden und sie im Vereinswesen und bei Veranstaltungen zu nutzen, ${ }^{25}$ was zweifelsfrei auch die wesentlichen Ziele des Witaj-Projekts umfasst. Das Beispiel des Niedersorbischen zeigt somit, dass Mikroliteratursprachen in ihrer soziodynamischen Beschaffenheit schwanken können, dass sie sich stets behaupten müssen, aber leider auch, dass man mit ihrem Verschwinden rechnen und dem entgegenwirken muss. ${ }^{26}$

\section{Obersorbisch}

Das Obersorbische (obs. hornjoserbšcina) ${ }^{27}$ unterscheidet sich in einigen Punkten vom Niedersorbischen, wenngleich wir es hier mit den beiden am engsten verwandten Mikroliteratursprachen im westslavischen Kontinuum zu tun haben, ${ }^{28}$ welche jeweils eine eigenständige kodifizierte Sprache hervorbrachten. Im Hinblick auf die Vitalität ist hier etwas mehr Optimismus zu erkennen als in der Niederlausitz, wenn

Měto Nowak merkt zu Recht an, dass diese Zahl durchaus erfreulich sei, bedenkt man die geringe Gesamtzahl der Gruppe sowie den begrenzten Anwendungsradius der Sprache. Ibidem.

LEWASZKIEWICZ, T.: Dolnołużycki i górnołużycki - języki zagrożone czy wymierające? Slavia Occidentalis, 2014, 71/1, S. 50.

26 Zum Erfolg des Witaj-Projekts in der Niederlausitz siehe SCHULZ, J.: Bilingualer Spracherwerb im Witaj-Projekt. Schriften des Sorbischen Instituts. Spisy Serbskeho instituta, 6o. Bautzen-Budyšin: Domowina, 2015.

27 Die ältesten Schriftdokumente des Obersorbischen datieren auf das 16. Jahrhundert, wichtige Texte entstanden später im Wittichenauer Dialekt der katholischen Sorben, so etwa eine vollständige Bibelübersetzung durch J. H. Swětlik. Zu Einzelheiten der Sprachgeschichte und zur Herausbildung unterschiedlicher schriftsprachlicher Tendenzen siehe LEWASZKIEWICZ, T.: Obersorbisch. In: OKUKA, M. (ed.): Wieser Enzyklopädie des Europäischen Ostens, 10. Lexikon der Sprachen des Europäischen Ostens. Klagenfurt: Wieser, 2002, S. 350-352.

28 Tadeusz Lewaszkiewicz sieht die Gründe für die Existenz zweier sorbischer Schriftsprachen in den teilweise markanten Systemunterschieden im niedersorbisch-obersorbischen Dialektkontinuum (LEWASZKIEWICZ, T.: Obersorbisch. In: OKUKA, M. (ed.): Wieser Enzyklopädie des Europäischen Ostens, 10. Lexikon der Sprachen des Europäischen Ostens. Klagenfurt: Wieser, 2002, S. 343). 
gegenwärtig etwa von rund 20.000 Sprechern die Rede ist. ${ }^{29}$ Das Obersorbische durchläuft gegenwärtig eine Phase der Revitalisierung, die in unterschiedlichem Ausmaß erfolgreich ist. ${ }^{30}$ Das Witaj-Projekt, welches in beiden Teilen der Lausitz einen wichtigen Beitrag zur weiteren Sprachpflege leistet, kann auch hier als Schlüsselinitiative gelten, die heute der Reduktion sprachlicher Kompetenzen entgegenwirken soll. Es lässt sich daher erkennen, dass das Vorhaben gleichermaßen als Bestandteil des organisierten Prozesses im Sinne Duličenkos verstanden werden kann, der aber in erster Linie in Opposition zur Existenzbedrohung einer Sprache steht. ${ }^{31}$ Mit anderen Worten ist also das Obersorbische weitestgehend noch nicht so stark von Attrition bedroht wie das Niedersorbische, dennoch darf es durchaus als gefährdete Sprache deklariert werden, ${ }^{32}$ wodurch wiederum das Witaj-Projekt seine absolute Berechtigung erfährt.

Der Zusammenhang mit der Erforschung slavischer Mikroliteratursprachen fällt auch in diesem Fall nicht mit Duličenkos Ansätzen in seinem Werk von 1981 zusammen, in dem die Existenz einer obersorbischen Mikroliteratursprache abgelehnt wird. ${ }^{33}$ In späteren Texten wird die Sprache hingegen als autonom betrachtet, was ähnlich wie im Fall des Niedersorbischen bis zu einem gewissen Grad kritisch betrachtet werden kann, stellt doch auch hier das Deutsche eine wichtige Dachsprache dar, welche insbesondere auf zahlreichen lexikalischen Gebieten Einflüsse ausübte und dies auch nach wie vor tut. Andererseits ist es bemerkenswert, dass es sich um eine der am weitesten ausgebauten Mikroliteratursprachen handeln muss, was wiederum den Autonomiestatus in funktionaler Hinsicht bekräftigt und in Duličenkos Tabelle dadurch ersichtlich wird, dass nahezu alle Anwendungsbereiche der Sprache mit einem Pluszeichen gekennzeichnet sind. ${ }^{34}$ Dies verweist auf

29 So bei GRAHL, S.: Werben fürs, Sorbentum: Über den Versuch, eine Minderheitensprache zu revitalisieren. In: ELMENTALER, M. (ed.): Deutsch und seine Nachbarn. Kieler Forschungen zur Sprachwissenschaft, 1. Frankfurt am Main: Peter Lang Verlag, 2009, S. 52.

30 Ibidem.

31 Roland Marti (MARTI, R.: Haut- et bas-sorabe: une cohabitation linguistique difficile. Revue des études slaves, 2014, LXXXV-2, S. 216) skizziert die Lage wie folgt: „[...] ce n'est que dans le «triangle catholique » entre Budyšin/Bautzen, Kamjenc/Kamenz et Wojerecy/Hoyerswerda qu'il y a encore une population sorabe linguistiquement viable [...]“.

32 LEWASZKIEWICZ, T.: Dolnotużycki i górnotużycki - języki zagrożone czy wymierające? Slavia Occidentalis, 2014, 71/1.

33 DULIČENKO, A. D.: Slavjanskije literaturnyje mikrojazyki. Voprosy formirovanija i razvitija. Tallin: Valgus, 1981, S. 16.

34 DULIČENKO, A. D.: Sovremennoje jazykoznanije i slavjanskije literaturnyje mikrojazyki. In: DULIČENKO, A. D. - GUSTAVSSON, S. (eds): Slavjanskije literaturnyje mikrojazyki i jazykovyje kontakty: Materialy meždunarodnoj konferencii, organizovannoj v ramkach Komissii po jazykovym kontaktam pri Meždunarodnom Komitete slavistov. Tartu, 15-17 sentjabrja $2005 \mathrm{~g}$. Slavica Tartuensia, VII. Tartu: Tartu Ülikooli Kirjastus, 2006, S. 42. 
einen hohen Grad an Sprachausbau und schriftlicher Verwendungsmöglichkeiten, unabhängig davon, wie sie genutzt werden. Lediglich zwei Fragezeichen finden sich hier, nämlich beim Unterpunkt „Alle Unterrichtsfächer“ und „Verwaltung“ (wobei gerade hier die Verwendung des Obersorbischen geläufig ist, worauf in der Verfassung des Freistaates Sachsen in offener Form Artikel 6 verweist, siehe dazu VERFASSUNG DES FREISTAATES SACHSEN: Dresden: Sächsischer Landtag, 2014). Es darf also summiert werden, dass das Obersorbische durchaus berechtigt als slavische Mikroliteratursprache klassifiziert wird, und das vor allem auf Grund seiner zwar komplex vorhandenen Schrifttradition, aber einer gleichzeitig eingeschränkten funktionalen Reichweite und einer schwankenden Vitalität.

\section{Kaschubisch}

Einen besonders interessanten Fall stellt das Kaschubische (kasch. kaszëbsczi jãzëk) dar, denn bereits im 15. Jahrhundert finden sich einige kaschubische Textfragmente wieder, bevor im 19. Jahrhundert wichtige Schritte auf dem Weg zur Kodifikation unternommen werden. ${ }^{35}$ Es werden u. a. Zeitschriften gedruckt, nach 1945 intensiviert sich die Publikationstätigkeit vor allem im Hinblick auf normative Regelwerke wie eine Anleitung zur Rechtschreibung, die Herausgabe von Wörterbüchern und die Übersetzung des Neuen Testaments im Jahre 1993. ${ }^{36}$ Die Angaben zu den Sprechern belaufen sich auf etwa $50.000,{ }^{37}$ während der Gesamtgruppe bis zu 500.00o Personen angehören könnten. ${ }^{38}$

Im Zusammenhang mit der weiträumigen Publikationstätigkeit, deren Ergebnisse sich heute auf zahlreichen Ebenen niedergeschlagen und im kleinen Maßstab verfestigt haben, betrachtet Duličenko das Kaschubische bereits 1981 als autonome Mikroliteratursprache und beruft sich besonders auf die umfangreichen Verschriftungsund Stabilisierungstendenzen. Diese konnten nach dem Umbruch zu Beginn der 1990er Jahre auch politisch geltend gemacht werden, was dazu führt, dass etappenweise

35 Die Hintergründe der Sprachgeschichte werden bei CYBULSKA-ROGOWSKA, E. - CYBULSKI, M.: fęzyk kaszubski. In: OCZKOWA, B. - SZCZEPAŃSKA, A. - KWOKI, T. (eds): Słowiańskie języki literackie. Rys historyczny. Kraków: Wydawnictwo Uniwersytetu Jagiellońskiego, 2011, S. 34-37 umrissen.

36 BREZA, E.: Das Kaschubische. In: REHDER, P. (ed.): Einführung in die slavischen Sprachen. Darmstadt: Wissenschaftliche Buchgesellschaft, 2006, S. 175-176.

37 Ibidem, S. 171. In der polnischen Volkszählung von 2011 bezeichnen sich 108.14o Personen als Sprecher des Kaschubischen, davon sehen sich aber nur 13.799 als Muttersprachler. GUDASZEWSKI, G.: Rozdziat IV. Przynależność narodowo-etniczna, język i wyznanie. In: CHMIELEWSKI, M. (ed.): Ludność. Stan i struktura demograficzno-społeczna. Narodowy Spis Powszechny Ludności i Mieszkań 2011. Warszawa: Główny Urząd Statystyczny, 2013, S. 96, 98.

38 LUBAŚ, W.: Kaschubisch. In: OKUKA, M. (ed.): Wieser Enzyklopädie des Europäischen Ostens, 10. Lexikon der Sprachen des Europäischen Ostens. Klagenfurt: Wieser, 2002, S. 265. 
immer neue Bereiche erschlossen werden, in denen die Sprache zur Anwendung kommt. Dazu zählen Textdokumente, die neu entstehen können und von Duličenko ${ }^{39}$ klassifiziert werden (so etwa Zeitungen, Zeitschriften, Lyrik und Prosa). Als besonders erfolgreich kann jedoch erstens die Einführung des Kaschubischen in den öffentlichen Raum gelten, denn aus diesem Grund prägen heute zweisprachige Ortsschilder die Region, was auch korrekt in der Tabelle bei Duličenko erfasst wird, und zweitens seine Verwendung im gymnasialen Unterricht (hier steht in der Tabelle ein Minuszeichen, es müsste jedoch durch ein Pluszeichen ersetzt werden, da das Abitur in kaschubischer Sprache abgelegt werden kann). ${ }^{40}$ In jedem Fall gilt es festzuhalten, dass die heutige Politik die sprachliche Entwicklung des Kaschubischen begünstigt, da es im polnischen Minderheitengesetz per definitionem als Regionalsprache betrachtet wird, ${ }^{41}$ was einschneidende Konsequenzen für seinen Anwendungsradius und für die Möglichkeiten seiner Förderung hat. Neben dem Schul- und Bildungswesen hier sei auf die Forschungstradition an der Danziger Universität verwiesen - hat sich das Kaschubische in seinen unterschiedlichen Anwendungsbereichen deutlich verfestigt, auch wenn wie bei allen anderen Mikroliteratursprachen Defizite erkennbar

39 DULIČENKO, A. D.: Sovremennoje jazykoznanije i slavjanskije literaturnyje mikrojazyki. In: DULIČENKO, A.D. - GUSTAVSSON, S. (eds): Slavjanskije literaturnyje mikrojazyki i jazykovyje kontakty: Materialy meždunarodnoj konferencii, organizovannoj v ramkach Komissii po jazykovym kontaktam pri Meždunarodnom Komitete slavistov. Tartu, 15-17 sentjabrja $2005 \mathrm{~g}$. Slavica Tartuensia, VII. Tartu: Tartu Ülikooli Kirjastus, 2006, S. 42.

40 Darüber berichtete die Gazeta Wyborcza bereits am 22.12.2004, zudem müsste es gegenwärtig Wojewodschaft Pommern (pln. Województwo pomorskie) heißen, denn die von Duličenko verwendete Bezeichnung Wojewodschaft Danzig (pln. Województwo gdańskie) war nur bis 1998 gebräuchlich (vgl. Гданьское воев. bei DULIČENKO, A. D.: Slavjanskaja mikrolingvistika i slavjanskaja mikrofilologija. Balkanistic Forum, 2017, 3, S. 12 und DULIČENKO, A. D.: Slavjanskaja mikrofilologija. In: DULIČENKO, A. D. - NOMATI, M. (eds): Slavjanskaja mikrofilologija. Slavica Tartuensia, XI - Slavic Eurasian Studies, 34. Tartu-Sapporo: Tartu Ülikooli Kirjastus - Hokkaido University Press, 2018, S. 4).

41 „Gesetz über die nationalen und ethnischen Minderheiten sowie über die Regionalsprache“vom o6. Januar 2005 mit einer präzisen Angabe darüber, was unter einer Regionalsprache in Polen zu verstehen ist. Es gilt als der bedeutendste Rechtsakt in Polen, der die Bedürfnisse nationaler und ethnischer Minderheiten regelt (NIJAKOWSKI, L. M.: Die Politik des polnischen Staates gegenüber den nationalen und ethnischen Minderheiten. Polen-Analysen 2016, 177, S. 4-5). Somit ist der von Duličenko erwähnte Autonomiestatus nicht gleich anzuzweifeln, allerdings sind für ihn ausschließlich periphere Mikroliteratursprachen als Regionalsprachen zu betrachten (DULIČENKO, A. D.: Slavjanskaja mikrolingvistika i slavjanskaja mikrofilologija. Balkanistic Forum, 2017, 3, S. 14; DULIČENKO, A. D.: Slavjanskaja mikrofilologija. In: DULIČENKO, A. D. - NOMATI, M. (eds): Slavjanskaja mikrofilologija. Slavica Tartuensia, XI - Slavic Eurasian Studies, 34. Tartu-Sapporo: Tartu Ülikooli Kirjastus - Hokkaido University Press, 2018, S. 5), und da er das Kaschubische als autonome und somit nicht als regionale Mikroliteratursprache sieht, steht diese Ansicht in gewisser Weise im Gegensatz zur polnischen Rechtsauffassung. Daher wäre der Begriffsapparat dahingehend zu überprüfen, ob nicht auch eine Orientierung an einer rechtlich standardisierten Terminologie erfolgen sollte, die in dem Staat, in dem eine Mikroliteratursprache verortet wird Gültigkeit erfährt, um so eine möglichst stringente definitorische Präzisierung zu gewährleisten. 
sind (etwa im Bereich der Lexik, der Obligatheit oder der Vitalität sowie des generell eingeschränkten Kommunikationsradius und der damit einhergehenden Dominanz des Polnischen auf sämtlichen gesellschaftlichen Ebenen). Dennoch macht die Klassifikation als slavische Mikroliteratursprache durchaus Sinn, wie die historische und die aktuelle Entwicklung auf kleinem Raum zeigen. Geht Jadwiga Zieniukowa ${ }^{42}$ noch davon aus, das Kaschubische befinde sich in statu nascendi, so kann man es heute durchaus als Mikroliteratursprache in esse bezeichnen. ${ }^{43}$

\section{Oberschlesisch}

Was das Oberschlesische (oberschl. Ślōnskŏ gŏdka) ${ }^{44}$ anbetrifft, so erklären sich sein umstrittener Status und die damit einhergehenden teilweise heftigen Diskussionen durch die Verquickung unterschiedlicher politischer, historischer und sozialer Komponenten. Gegenwärtig erleben wir eine Renaissance des Oberschlesischen sowie damit einhergehende intensive Ansätze, den spezifischen Dialekt ${ }^{45}$ der Region zu kodifizieren. Heutzutage kämpft eine überschaubare Gruppe von Kodifizierern mit teilweise beachtlichen Erfolgen für die Hebung des Prestiges des Oberschlesischen und für seine Einführung in den öffentlichen Raum, was unter anderem dazu geführt hat, dass 846.719 Personen bei der letzten Volkszählung eine oberschlesische Nationalität und

42 ZIENIUKOWA, J.: Kaszubszczyzna. In: GAJDA, S. (ed.): Język polski. Najnowsze dzieje języków słowiańskich. Opole: Uniwersytet Opolski - Instytut Filologii Polskiej, 2001.

43 Diese Einschätzung stützt sich sowohl auf die heutigen Rahmenbedingungen, unter denen das Kaschubische sich entwickelt, aber auch auf die Schritte, die zu seiner Straffung in zahlreichen Anwendungsbereichen beigetragen haben, etwa im Hinblick auf seine weitreichende Normierung, die Festlegung auf eine einheitliche Orthographie oder seine Einführung in das Schulwesen. Hanna Dalewska-Greń kommt bereits 1997 zu einer ähnlichen Einschätzung: „Za żywy mikrojęzyk na obszarze zachodniej Słowianszczyźnie można natomiast uznać język literacki oparty na dialektach kaszubskich“"(DALEWSKA-GREŃ, H.: Jęzki stowiańskie. Warszawa: Wydawnictwo Naukowe PWN, 1997, S. 586).

44 Hier geht es ausschließlich um die Varietäten, die im oberschlesischen Industriegebiet verwendet werden und nicht um die Mundarten im schlesischen Teil der Tschechischen Republik. Die Orthographie der Eigenbezeichnung kann auf Grund fehlender Normwerke schwanken, weshalb hier die Version wiedergegeben wird, die im möglicherweise konsensfähigen Alphabet erscheint, welches von der Vereinigung Pro Loquela Silesiana entwickelt wurde und auch als ślabikŏrzowy szrajbōnek bezeichnet wird.

45 In der polnischen Dialektologie wird die Gesamtheit der schlesischen Dialekte als eine von fünf historischen Kerndialektzonen des Polnischen betrachtet (DEJNA, K.: Dialekty polskie. Wrocław: Zakład Narodowy im. Ossolińskich, 1993, S. 86). In aktuellen Studien wird insbesondere von der Kattowitzer Sprachwissenschaftlerin Jolanta Tambor davon ausgegangen, man müsse das Oberschlesische als einen Ethnolekt betrachten (TAMBOR, J.: German Elements in the Silesian Ethnolect. In: KACZMARSKA, E. - NOMACHI, M. (eds): Slavic and German in Contact: Studies from Areal and Contrastive Linguistics. Slavic Eurasian Studies, 26. Sapporo: Hokkaido University Press, 2014, S. 135-164). 
529.377 Personen das Oberschlesische als zumindest eine ihrer Sprachen deklarierten. ${ }^{46}$ Diese Tendenzen können in der Erforschung der Mikroliteratursprachen nicht unberücksichtigt bleiben, spiegeln sie doch einige interessante sprachpolitische Dynamiken und gesellschaftliche Veränderungen wider, die nicht immer in dieser Form möglich, im Falle Oberschlesiens sogar lange Jahre undenkbar waren. Daher verwundert die ursprüngliche Einschätzung Duličenkos auch nicht, wenn er in seiner Arbeit aus dem Jahr 1981 recht knapp skizziert, warum es vollkommen ausgeschlossen sei, den oberschlesischen Idiomen den Status als Mikroliteratursprache anzuerkennen. Die Begründung dafür lautet, dass massive Germanisierungstendenzen vor Ort dazu geführt hätten, dass die deutsche Seite vom unscharf definierten sprachlichen und ethnischen Bewusstsein der lokalen Bevölkerung profitieren wollte und Sprachen erfunden habe, was wiederum separatistische Tendenzen beschleunigt hätte. Gerade deshalb habe man überhaupt erst begonnen, von einer wasserpolnischen Sprache auszugehen.$^{47}$ In neueren Publikationen wird dementgegen ein bemerkenswerter Paradigmenwechsel eingeleitet, wenn in den Ausführungen in unterschiedlicher Intensität das Vorhandensein einer peripheren oberschlesischen Mikroliteratursprache attestiert wird ${ }^{48}$ allerdings erfolgt keine Aufnahme des

46 Detailliert bei GUDASZEWSKI, G.: Rozdziat IV. Przynależność narodowo-etniczna, język i wyznanie. In: CHMIELEWSKI, M. (ed.): Ludność. Stan i struktura demograficzno-społeczna. Narodowy Spis Powszechny Ludności i Mieszkań 2011. Warszawa: Główny Urząd Statystyczny, 2013.

47 DULIČENKO, A. D.: Slavjanskije literaturnyje mikrojazyki. Voprosy formirovanija i razvitija. Tallin: Valgus, 1981, S. 96-97. Verwiesen wird hier zudem auf den Terminus des Schlonsakischen, der laut Duličenko ähnlich verwendet worden sei wie der des Wasserpolnischen. Erklärt wird aber nicht, dass gerade der Begriff Wasserpolnisch anfänglich nicht negativ, sondern geographisch motiviert war und sich auf die polnischen Varietäten bezog, die an der Oder (also am Wasser) gesprochen wurden (auch wenn der Begriff später zu einer „verwässerten“ Sprachform umgedeutet und somit abgewertet wurde; HENTSCHEL, G.: Vorwort. In: HENTSCHEL, G. (ed.): Variation und Stabilität in Kontaktvarietäten. Beobachtungen zu gemischten Formen der Rede in Weißrussland, der Ukraine und Schlesien. Beiträge zu einem „Thematischen Block“ auf dem XV. Internationalen Slavistentag in Minsk, Weißrussland, August 2013. Studia Slavica Oldenburgensia, 21. Oldenburg: BIS-Verlag der Carl-von-Ossietzky-Universität, 2013, S. iii).

48 DULIČENKO, A. D.: Slavjanskaja mikrolingvistika i slavjanskaja mikrofilologija. Balkanistic Forum, 2017, 3, S. 15; DULIČENKO, A. D.: Slavjanskaja mikrofilologija. In: DULIČENKO, A. D. NOMATI, M. (eds): Slavjanskaja mikrofilologija. Slavica Tartuensia, XI - Slavic Eurasian Studies, 34. Tartu-Sapporo: Tartu Ülikooli Kirjastus - Hokkaido University Press, 2018, S. 6. An beiden hier zitierten Stellen heißt es bei Duličenko weiterhin, dass das Oberschlesische in Polen und in der Tschechischen Republik gesprochen werde und dass es seit 2010 eine Kodifikation in Form von Lehrwerken gäbe. Auch wenn ein Teil Schlesiens in der Tschechischen Republik liegt, so lassen sich dort gegenwärtig keinerlei vergleichbare Tendenzen beobachten, und auch die Lehrwerke aus dem Jahr 2010 sind letztlich als Probeversionen konzipiert, um die neu entwickelte Orthographie testen zu lassen (siehe dazu im Vorwort des Lehrwerks bei ADAMUS, R. et al.: Górnoślōnski ślabikŏrz. Chorzów: Pro Loquela Silesiana, 2010, S. 3; eine Neuauflage wurde bereits getestet). Eine Kodifikation mit verbindlichen Regeln existiert nach wie vor nicht, was als ein wesentliches Argument der polnischen Regierung verwendet wird, um die Frage nach einem separaten Sprachstatus klar zu verneinen 
Oberschlesischen in die schematische Tabellenübersicht, ${ }^{49}$ so dass dort ein Vergleich mit anderen westslavischen Mikroliteratursprachen ausbleiben muss. Dennoch lassen sich einige Phänomene erkennen, die das Oberschlesische und seine Verwendung im kleinen Rahmen charakterisieren: So beobachten wir seit einigen Jahren eine produktive Tätigkeit unterschiedlicher Personen und Gruppen, die sich enorm um eine Verschriftung des Oberschlesischen bemühen und Zeitungen, Wörterbücher und Lehrwerke für Schüler herausgeben, zudem entstehen wissenschaftliche Sammelbände, die der Frage gewidmet sind, wie man die Varietät systemlinguistisch betrachten soll, welchen Status man sich in Zukunft wünscht und wie eine bisher immer noch nicht erfolgte Standardisierung realisiert werden kann. Vor allem die hohe Bereitschaft einiger lokaler Aktivisten ist es jedoch, die einen organisierten Prozess im Sinne der Mikroliteratursprachlichkeit erkennen lässt. Hier wird offen und lautstark das Ziel verfolgt, das Prestige der Idiome der Region zu erhöhen, das Oberschlesische zu einer regionalen Minderheitensprache auszubauen, die Oberschlesier als eigenständige Gruppe $^{50}$ anzuerkennen und regelmäßige Veranstaltungen durchzuführen, die auf den singulären Charakter des Oberschlesischen und seiner angestammten Bevölkerung verweisen, so etwa den Autonomiemarsch, der des Sonderstatus der Region zu Beginn der 1920er Jahre gedenken soll und sich mehr und mehr als ein Forum für Autonomieanhänger entpuppt. ${ }^{51}$ Im öffentlichen Raum aufmerksam auf sich $\mathrm{zu}$ machen und möglichst viele neue Anhänger zu gewinnen ist eines der Ziele der Sprachautonomisten, deren Aktivitäten schließlich auch darin münden sollen,

(CZĄSTKA-SZYMON, B.: Opinia o projekcie zmiany Ustawy o mniejszościach narodowych i etnicznych oraz o języku regionalnym, a także niektórych innych ustaw. LingVaria, 2013, 1 (15), S. 185-198). Dennoch scheint sich der Orthographievorschlag, der im Lehrbuch von Adamus et al. angewendet wird, als konsensfähig zu erweisen, vgl. dazu Fußnote 44 .

49 Etwa bei DULIČENKO, A.D.: Vvedenije v slavjanskuju filologiju. Učebnoje posobije. Moskva: Flinta-Nauka, 2016, S. 600-601.

50 Dazu gab es bereits einige Überlegungen, etwa die der Einforderung einer oberschlesischen Nation oder einer oberschlesischen ethnischen Minderheit. Nachdem der polnische Sejm einen konkreten Antrag auf die Anerkennung als eigene Nation verwarf, versuchte man, sich unter Bezugnahme anderer Begriffe ein Anrecht auf einen Sonderstatus zu verschaffen, außerdem wurden Petitionen abgehalten, die den Sejm dazu zwingen sollen, sich auf höchster Ebene mit dem Anliegen zu befassen. Die Ergebnisse stehen noch aus, dürften aber Dank des hohen Rückhaltes in der lokalen Bevölkerung auch zukünftig für politischen Sprengstoff sorgen. Als Plattform für die Streuung dieser Ideen wird u. a. der Autonomiemarsch genutzt, der alljährlich in Katowice Gleichgesinnte versammelt und auf dem die politisch ausgesprochen aktive Oberschlesische Autonomiebewegung (pln. Ruch Autonomii Śląska, kurz $R A S$ ) keine Gelegenheit verstreichen lässt, für mehr Eigenständigkeit der - wie es hier heißt - oberschlesischen Sprache zu werben (HENZELMANN, M.: Authentizität als treibende Kraft bei der Herausbildung slavischer Mikroliteratursprachen (am Beispiel des Pomakischen und des Schlesischen). Specimina Philologiae Slavicae, 185. München et al.: Verlag Otto Sagner, 2015, S. 258-271).

51 Detailliert bei ibidem, S. $177-285$. 
weitere Befürworter für den Sprachausbau zu finden und so eine möglichst große Gruppe von Unterstützern um sich zu wissen. ${ }^{52}$ All diese Umstände verdeutlichen die Dynamik, welche in der Forschungstradition rund um die Mikroliteratursprachen berücksichtigt werden muss, wenngleich es künftig hilfreich wäre, inhaltliche Komponenten näher zu beleuchten und Sachverhalte darzulegen, die einen derartigen Wandel hervorrufen und somit die gegenwärtige Klassifikation des Oberschlesischen begründen könnten, schließlich ist es bekannt, dass gerade in der polnischen Dialektologie den oberschlesischen Mundarten eine Sonderrolle zukommt, die nicht ohne fundierte Argumente verworfen werden wird. Hinzu kommt ein wesentlicher Aspekt, nämlich die geopolitischen Tatsachen, mit denen gerade in Oberschlesien spezifische Identitätskonzepte verwoben sind, ${ }^{53}$ welche sich gleichermaßen auf soziolinguistische Phänomene auswirken und in ihrer heutigen Ausprägung ein völliges Novum in Polen darstellen, welches in der Mikroliteratursprachenforschung unbedingt Beachtung finden sollte. Man kann sich daher den Worten Jolanta Tambors anschließen, die das Oberschlesische als Sprache in statu nascendi bezeichnet, ${ }^{54}$ da es bereits jetzt als defizitäre Mikroliteratursprache gelten kann. ${ }^{55}$

\section{Lachisch}

Die lachischen Mundarten (tsch. lašská nářečí, in Mundarttexten auch lašsky jazyk), welche sich im Nordosten Mährens bis an das tschechisch-polnische Grenzgebiet erstrecken, wurden vor allem ab den 1930er Jahren in Schriftform gebraucht, um literarische Texte in der Mundart zu konzipieren. In erster Linie ist hier der Name Óndra Łysohorsky (bürgerlich Erwin Goj) zu nennen, welcher als Vorreiter erster

52 HENZELMANN, M.: Das Schlesische als Sonderfall in der slavischen Mikrosprachenforschung. In: KUSSE, H. - SCHARLAJ, M. (ed.): Linguistische Beiträge zur Slavistik. XXIII. JungslavistInnen-Treffen in Dresden, 18.-20. September 2014. Specimina Philologiae Slavicae, 188. Leipzig: Biblion Media, 2016, S. 104.

53 In einer aktuellen Studie von Andrzej Rykała und Marek Sobczyński wird unter Verwendung von Kartenmaterial ausgewertet, welche Motive retroperspektiv und gegenwärtig die Besonderheiten der oberschlesischen Identität erklären können. Diese sind gleichermaßen eng an die Frage nach sprachlichen Optionen gebunden (RYKAŁA, A. - SOBCZYŃSKI, M.: Naród polski jako żywa struktura. Kszattowanie się poczucia odrębności narodowej Ślązaków pod wptywem uwarunkowań geograficzno-historycznych i geograficzno-politycznych. In: RYKAŁA, A. (ed.): Mniejszości narodowe i etniczne w interpretacjach przestrzennych. Studia z Geografii Politycznej i Historicznej, 5. Łódź: Wydawnictwo Uniwersytetu Łódzkiego, 2016, S. 161-162).

54 TAMBOR, J.: German Elements in the Silesian Ethnolect. In: KACZMARSKA, E. - NOMACHI, M. (eds): Slavic and German in Contact: Studies from Areal and Contrastive Linguistics. Slavic Eurasian Studies, 26. Sapporo: Hokkaido University Press, 2014, S. 137.

55 HENZELMANN, M.: Authentizität als treibende Kraft bei der Herausbildung slavischer Mikroliteratursprachen (am Beispiel des Pomakischen und des Schlesischen). Specimina Philologiae Slavicae, 185. München et al.: Verlag Otto Sagner, 2015, S. 285. 
Verschriftungstendenzen des Lachischen dank seiner intensiven Literaturproduktion gelten kann. Hanna Dalewska-Greń ${ }^{56}$ spricht sogar davon, dass es sich hierbei um den interessantesten Fall im Paradigma der Mikroliteratursprachen überhaupt handelt, denn Łysohorsky sei mit seinem Enthusiasmus der erste Verfechter und Erfinder solch einer Sprache gewesen, die weitestgehend für das literarische Schaffen verwendet wurde.$^{57}$ Es ist hervorzuheben, dass Łysohorsky sich verweigerte, Tschechisch zu schreiben und daher eigene Innovationen an den Tag legte, weiterhin schlossen sich seinen Ideen Autoren und Publizisten an, die Ende der 1930er Jahre die Gesellschaft Laško perspektywa gründeten und sich dem literarischen Schaffen widmeten. ${ }^{58}$ Aus dem Beitrag von Kevin Hannan geht deutlich hervor, dass das Lachische ausschließlich im Rahmen der schönen Literatur Anwendung fand, so dass es keinerlei andere gesellschaftliche Bereiche gab, die von der Varietät schriftlich bedient wurden, so dass er festhält:

[...] the recent development of Lachian is clearly that of a Czech dialect. ${ }^{59}$

Im Hinblick auf die Zuordnung des Lachischen geht Duličenko von einer peripheren bzw. regionalen Mikroliteratursprache aus, ${ }^{60}$ die sich im Aussterben befindet. ${ }^{61}$ In der Klassifikationstabelle mit einzelnen sprachlichen Anwendungsgebieten wird ihr lediglich eine Verwendung in den Bereichen der Literatur (Lyrik und zum Teil Erzählungen) sowie in der Privatkommunikation attestiert. ${ }^{62}$ Mit anderen

56 DALEWSKA-GREŃ, H.: Jezzki stowiańskie. Warszawa: Wydawnictwo Naukowe PWN, 1997, S. 586.

57 Kevin Hannan verweist in seiner Studie auf das Fehlen einer Grammatik, das Łysohorsky zu kompensieren versuchte, indem er seinen frühen Texten grammatische Anmerkungen und Wörterverzeichnisse hinzufügte, weshalb der Autor auch von „Łysohorsky’s literary language“ spricht. Es bleibt aber dennoch festzuhalten, dass Łysohorsky das Lachische als eigenständige Sprache betrachtete, obwohl die politischen Rahmenbedingungen im zentralistisch ausgerichteten kommunistischen Regime denkbar ungünstig für sein Schaffen waren. Auf Grund zahlreicher soziodynamischer Änderungen summiert Hannan, dass es fraglich sei, ob künftige Generationen sich mit dem Lachischen wie es von Łysohorsky geschrieben wurde identifizieren werden (HANNAN, K.: The Lachian Literary Language of Óndra Eysohorsky. The Slavic and East European Journal, 40, 4, 1996, S. 736-738).

58 Ibidem, S. 726-727.

59 Ibidem, S. 733.

60 DULIČENKO, A. D.: Slavjanskaja mikrofilologija. In: DULIČENKO, A.D. - NOMATI, M. (eds): Slavjanskaja mikrofilologija. Slavica Tartuensia, XI - Slavic Eurasian Studies, 34. Tartu-Sapporo: Tartu Ülikooli Kirjastus - Hokkaido University Press, 2018, S. 6.

61 DULIČENKO, A. D.: Slavjanskaja mikrolingvistika i slavjanskaja mikrofilologija. Balkanistic Forum, 2017, 3, S. 14 .

62 DULIČENKO, A. D.: Sovremennoje jazykoznanije i slavjanskije literaturnyje mikrojazyki. In: DULIČENKO, A. D. - GUSTAVSSON, S. (eds): Slavjanskije literaturnyje mikrojazyki i jazykovyje kontakty: Materialy meždunarodnoj konferencii, organizovannoj v ramkach Komissii po jazykovym kontaktam pri Meždunarodnom Komitete slavistov. Tartu, 15-17 sentjabrja $2005 \mathrm{~g}$. Slavica Tartuensia, VII. Tartu: Tartu Ülikooli Kirjastus, 2006, S. 42. 
Worten bedeutet das, dass wir es mit einer Varietät zu tun haben, die überhaupt nur für literarisches Schaffen in Schriftform verwendet wurde und ansonsten Teil eines mündlichen Dialektkontinuums ist, als welche sie in der tschechischen Sprachwissenschaft umfangreich beschrieben wurde. ${ }^{63}$ Betrachtet man Duličenkos eingangs zitierte Definition einer slavischen Mikroliteratursprache, so wird ersichtlich, dass für ihn die literarische Textproduktion noch kein hinreichendes Kriterium ist, um eine Mikroliteratursprache zu erkennen, denn es bedarf laut seiner Einschätzung eines organisierten Prozesses, der darüber hinaus geht und das Ziel verfolgt, weitere Bereiche des alltäglichen Lebens schriftlich zu bedienen. ${ }^{64}$ Genau dieser Prozess bleibt aber aus, denn es wurde niemals eine Grammatik erschaffen, auch Regelwerke entstanden nicht, und auch der Versuch, einen Sprachausbau auf multiplen Ebenen zu initiieren blieb aus. Initiativen wie das Witaj-Projekt in der Lausitz wurden nie durchgeführt, im Gegensatz zum Kaschubischen gibt es auch keine Möglichkeit, das Lachische offiziell zu verwenden, und vor allem lässt sich keine gesellschaftliche Tragweite wie im Falle des Oberschlesischen beobachten, die als Grundlage für konkrete Forderungen nach sprachlicher Autonomie geltend gemacht werden könnte. Eine lachische Mikroliteratursprache ist daher zwar aus diachroner Perspektive eventuell mit Einschränkungen und einer entsprechenden Auslegung des definitorischen Ansatzes denkbar, synchron allerdings nicht vorhanden. ${ }^{65}$ Daran zeigt sich, dass nicht alle Projekte des Sprachausbaus glücken und dass es unter Umständen erforderlich wird, den Begriffsapparat in zeitlichen Abständen wiederholt zu prüfen, ggf. zu revidieren, oder aber von punktuellen Phänomenen auszugehen, die sich sowohl weiter entwickeln können ${ }^{66}$ oder aber wohl verschwinden werden. ${ }^{67}$

63 Überblick bereits bei LAMPRECHT, A.: K otázce lašských nářečí. Slovo a slovesnost, 16/3, 1955, $140-146$.

64 DULIČENKO, A. D.: Osnovy slavjanskoj filologii. Lingvističeskaja problematika. Vol. 2. Opole: Uniwersytet Opolski - Instytut Filologii Polskiej. Opolskie Towarzystwo Przyjaciół Nauk, 2011, S. 318-319.

65 Ich danke einem der anonymen Rezensenten für seine Anmerkung, die Klassifikation des Lachischen als Mikroliteratursprache sei eine Fehleinschätzung Duličenkos, da es hier vielmehr um eine künstlerische Verwendung der Mundart ging. Diese Darstellung spiegelt letztlich auch altbekannte Positionen der bohemistischen Linguistik wider. Demnach passen die Rahmenbedingungen des Lachischen auch nicht zu der oben zitierten Definition einer Mikroliteratursprache und machen das Gesamtproblem grundsätzlich diskutabel.

66 Wie für das Lachische angenommen bei DULIČENKO, A. D.: Lachisch. In: OKUKA, M. (ed.): Wieser Enzyklopädie des Europäischen Ostens, 10. Lexikon der Sprachen des Europäischen Ostens. Klagenfurt: Wieser, 2002, S. 290.

67 Wie für den Fall des Lachischen vermutet von DULIČENKO, A. D.: Slavjanskaja mikrolingvistika i slavjanskaja mikrofilologija. Balkanistic Forum, 2017, 3, S. 14. 


\section{Ostslowakisch}

Die ostslowakischen Mundarten (slk. východoslovenské nárečia bzw. východoslovenčina) bilden neben den west- und mittelslowakischen eine der drei großen Dialektzonen des Landes, die zum traditionellen gesamtslowakischen Areal gezählt werden. ${ }^{68}$ Hier haben sich bereits im 15. Jahrhundert eigene schriftsprachliche Ansätze entwickelt, die zahlreiche phonetische und lexikalische Besonderheiten aufweisen und die in unterschiedlicher Intensität aufgearbeitet wurden. ${ }^{69}$ Zudem ist die Produktivität ostslowakischer Autoren im 18. Jahrhundert zu nennen, die dazu geführt hat, dass der Regionalismus auch in sprachlicher Hinsicht entstehen und verfestigt werden konnte. $^{70}$ In erster Linie ist hier die Textproduktion calvinistischer Slowaken zu erwähnen, die bis in die 1920er Jahre eine wichtige Rolle spielt und die Existenz einer ostslowakischen Mikroliteratursprache begründet, die heute jedoch nicht mehr verwendet wird. ${ }^{71}$ Dieser Schrifttradition trägt Duličenko Rechenschaft und klassifiziert das Ostslowakische als periphere Mikroliteratursprache, in der lyrische Texte, Erzählungen und Zeitschriften vorhanden sind und die als Kirchensprache, teilweise in Vereinen und in der Privatkommunikation verwendet wird. ${ }^{72}$ Was allerdings heute fehlt - und das ist ein gravierender Punkt - sind normative Regelwerke, die einen Schriftgebrauch plausibel erläutern und ausbaufähig machen würden, ${ }^{73}$ hinzu kommt, dass es scheinbar keine gesellschaftliche Initiative in

68 BUFFA, F.: Východoslovenské nárečia. Vlastivedný časopis, 1962, 9, S. 1; RIPKA, I.: Na počiatku bola dialektológia... alebo Dialektika dejín disciplíny. In: OLOŠTIAK, M. - IVANOVÁ, M. - SLANČOVÁ, D. (eds): Vidy jazyka a jazykovedy. Na počest̉ Miloslavy Sokolovej. Acta Facultatis philosophicae universitatis Prešoviensis, Jazykovedný zborník, 34. Prešov: Filozofická fakulta Prešovskej univerzity v Prešove, 2011, S. 42.

69 TÓBIK, Š.: Východoslovenské nárečia. (Úvod do ich d'alšieho výskumu a štúdia). Nové obzory, 1965, 7, S. 255; Problemabriss außerdem bei DULIČENKO, A. D.: Ostslowakisch. In: OKUKA, M. (ed.): Wieser Enzyklopädie des Europäischen Ostens, 10. Lexikon der Sprachen des Europäischen Ostens. Klagenfurt: Wieser, 2002, S. 355-358.

70 BOSÁK, J. et al.: Slovenský jazyk. Redaktor naukowy Ján Bosák. Najnowsze dzieje języków słowiańskich. Opole: Uniwersytet Opolski - Instytut Filologii Polskiej, 1998, S. 117.

71 DALEWSKA-GREŃ, H.: Jezyki stowiańskie. Warszawa: Wydawnictwo Naukowe PWN, 1997, S. 586.

72 DULIČENKO, A. D.: Sovremennoje jazykoznanije i slavjanskije literaturnyje mikrojazyki. In: DULIČENKO, A.D. - GUSTAVSSON, S. (eds): Slavjanskije literaturnyje mikrojazyki i jazykovyje kontakty: Materialy meždunarodnoj konferencii, organizovannoj v ramkach Komissii po jazykovym kontaktam pri Meždunarodnom Komitete slavistov. Tartu, 15-17 sentjabrja $2005 \mathrm{~g}$. Slavica Tartuensia, VII. Tartu: Tartu Ülikooli Kirjastus, 2006, S. 42. In einem aktuellen Beitrag erfährt diese Zuordnung den Zusatz, es handele sich um eine Mikroliteratursprache, die sich schwach entwickele und vom Verschwinden bedroht sei DULIČENKO, A. D.: Slavjanskaja mikrolingvistika i slavjanskaja mikrofilologija. Balkanistic Forum, 2017, 3, S. 15.

73 Obwohl es auch dafür Ansätze und Publikationen gab, so etwa eine Grammatik von 1875 auf der Grundlage der Mundart von Šariš, die allerdings in ungarischer Sprache verfasst wurde, aber auch eine Grammatik aus dem Jahr 1941, die eine echte Perspektive für die weitere Kodifikation 
der Slowakei gibt, die einen ernsthaften Sprachausbau vorantreibt ${ }^{74}$ und einen organisierten Prozess im Sinne der Forschungstradition erkennen ließe.

\section{Fazit: Möglichkeiten und Grenzen eines Paradigmas im westslavischen Sprachraum}

Im Rahmen der Konzeptualisierung westslavischer Mikroliteratursprachen lässt sich erkennen, dass das Hervorbringen von Textdokumenten ein wesentliches Argument für ihre gegenwärtige Klassifikation darstellt. Sämtliche Varietäten, die in unterschiedlicher Intensität eine Textproduktion vorzuweisen haben, werden in den Kanon aufgenommen, so dass die beiden sorbischen Sprachen in Deutschland, das Kaschubische und das Oberschlesische in Polen, das Lachische in der Tschechischen Republik sowie das Ostslowakische in der Slowakei das Gesamtparadigma nach Duličenko abbilden. Es soll an dieser Stelle für einen elastischen Umgang mit den jeweiligen Zuordnungskriterien in Anlehnung an Duličenko ${ }^{75}$ plädiert werden, um Einschätzungen verschiebbar und temporär zu deuten, da es sich letztlich um Variablen handelt, die je nach Sprecherbedürfnissen ausgebaut oder aber verworfen werden müssen, was gleichermaßen bedeutet, dass nicht nur neue Mikroliteratursprachen hinzu kommen, sondern dass sie auch wieder aus dem Kanon verschwinden können, was bislang jedoch kaum kommentiert wurde. Es darf daher vermutet werden, dass kanonisierte Parameter nicht in aeternum gesellschaftsdynamischen Veränderungen standhalten können und dass eintretenden Neuerungen Rechenschaft getragen werden muss, um die Perspektiven und Rahmenbedingungen von Minderheitensprechern in der Slavia zu interpretieren, woraus sich aus gegenwärtiger Sicht folgende

hätte darstellen können, was allerdings durch die Entwicklungen nach 1945 verhindert wurde. Das Schrifttum wurde bis zu Beginn des 20. Jahrhunderts vor allem von Emigranten in den USA fortgesetzt (DULIČENKO, A. D.: Ostslowakisch. In: OKUKA, M. (ed.): Wieser Enzyklopädie des Europäischen Ostens, 10. Lexikon der Sprachen des Europäischen Ostens. Klagenfurt: Wieser, 2002, S. 356-357).

74 Die Vereinigung Vichodoslovenske združeňe VALAL verwendet auf ihrer Internetseite $<\mathrm{http}$ ://ilonas. net/valal/index.html> die Mundart und stellt Publikationen aus dem Bereich schöne Literatur und Theaterstücke vor - letztere könnten in Duličenkos Tabelle integriert und in der entsprechenden Rubrik mit einem Pluszeichen versehen werden, da etwa die Theatergruppe KL'UD (kurz für Kladzanske L'Udove Divadlo) seit 1998 Theaterstücke und Komödien aufführt (<http://www.klud.cc/>). Weiterhin werden Personen aufgelistet, die mit dem Ostslowakischen und seiner Erforschung zu tun haben. Ein organisierter Prozess zur Straffung normativer Konturen wird in den Internetauftritten jedoch nicht propagiert.

75 DULIČENKO, A. D.: Vvedenije v slavjanskuju filologiju. Učebnoje posobije. Moskva: Flinta-Nauka, 2016, S. 600-601, s. o. 
Einschätzung für die momentan klassifizierten westslavischen Mikroliteratursprachen und ihren synchronen Status ergibt: ${ }^{76}$

\begin{tabular}{llll}
\hline Staat & Varietät & $\begin{array}{l}\text { furistischer } \\
\text { Status }\end{array}$ & $\begin{array}{l}\text { Status als Mikro- } \\
\text { literatursprache }\end{array}$ \\
\hline Deutschland & Niedersorbisch & $\begin{array}{l}\text { Anerkannte } \\
\text { Minderheiten- } \\
\text { sprache }\end{array}$ & in statu moriendi \\
\hline Deutschland & Obersorbisch & $\begin{array}{l}\text { Anerkannte } \\
\text { Minderheiten- } \\
\text { sprache }\end{array}$ & in esse \\
\hline Polen & Kaschubisch & $\begin{array}{l}\text { Anerkannte } \\
\text { Regionalsprache }\end{array}$ & in esse \\
\hline Polen & Oberschlesisch & - & in statu nascendi \\
\hline Tschechische & Lachisch & - & vacat \\
Republik & & vacat \\
\hline Slowakei & Ostslowakisch & - &
\end{tabular}

Diese Einschätzung gilt freilich nicht als invariabel, sie muss in künftigen Studien überprüft und auf soziolinguistische Neuerungen abgestimmt werden. Ungeachtet dessen soll sie einen aktuellen Eindruck von der gegenwärtigen Situation in der Westslavia und den dort verorteten Mikroliteratursprachen geben und für eine weiträumige und ergebnisoffene Untersuchung des Gegenstands plädieren, da momentan vor dem Hintergrund der postulierten Begriffsdefinition im westslavischen Sprachraum lediglich vier an Stelle von sechs slavischen Mikroliteratursprachen verortet werden können.

76 Auch hierfür gilt natürlich, dass die Darstellung umsichtig interpretiert werden muss und keinen Anspruch auf Unveränderlichkeit erhebt. 


\section{Literatur:}

ADAMUS, R. et al.: Górnoślōnski ślabikŏrz. Chorzów: Pro Loquela Silesiana, 2010.

BOSÁK, J. et al.: Slovenský jazyk. Redaktor naukowy Ján Bosák. Najnowsze dzieje języków słowiańskich. Opole: Uniwersytet Opolski - Instytut Filologii Polskiej, 1998.

BREZA, E.: Das Kaschubische. In: REHDER, P. (ed.): Einführung in die slavischen Sprachen. Darmstadt: Wissenschaftliche Buchgesellschaft, 2006, S. 171-177.

BUFFA, F.: Východoslovenské nárečia. Vlastivedný časopis, 1962, 9, S. 1-4.

CRYSTAL, D.: Language Death. Cambridge: Cambridge University Press, 2000.

CYBULSKA-ROGOWSKA, E. - CYBULSKI, M.: Jezyk kaszubski. In: OCZKOWA, B. SZCZEPAŃSKA, A. - KWOKI, T. (eds): Słowiańskie języki literackie. Rys historyczny. Kraków: Wydawnictwo Uniwersytetu Jagiellońskiego, 2011, S. 29-42.

CZĄSTKA-SZYMON, B.: Opinia o projekcie zmiany Ustawy o mniejszościach narodowych i etnicznych oraz o języku regionalnym, a także niektórych innych ustaw. LingVaria, 2013, 1 (15), S. 185-198.

DALEWSKA-GREŃ, H.: Jezyki stowiańskie. Warszawa: Wydawnictwo Naukowe PWN, 1997.

DEJNA, K.: Dialekty polskie. Wrocław: Zakład Narodowy im. Ossolińskich, 1993.

DULIČENKO, A. D.: Lachisch. In: OKUKA, M. (ed.): Wieser Enzyklopädie des Europäischen Ostens, 10. Lexikon der Sprachen des Europäischen Ostens. Klagenfurt: Wieser, 2002, S. 287-290.

DULIČENKO, A. D.: Osnovy slavjanskoj filologii. Lingvističeskaja problematika. Vol. 2. Opole: Uniwersytet Opolski - Instytut Filologii Polskiej. Opolskie Towarzystwo Przyjaciół Nauk, 2011.

DULIČENKO, A. D.: Ostslowakisch. In: OKUKA, M. (ed.): Wieser Enzyklopädie des Europäischen Ostens, 10. Lexikon der Sprachen des Europäischen Ostens. Klagenfurt: Wieser, 2002, S. 355-358.

DULIČENKO, A. D.: Slavjanskaja mikrofilologija. In: DULIČENKO, A. D. - NOMATI, M. (eds): Slavjanskaja mikrofilologija. Slavica Tartuensia, XI - Slavic Eurasian Studies, 34. Tartu-Sapporo: Tartu Ülikooli Kirjastus - Hokkaido University Press, 2018, S. 3-18.

DULIČENKO, A. D.: Slavjanskaja mikrolingvistika i slavjanskaja mikrofilologija. Balkanistic Forum, 2017, 3, S. 9-18.

DULIČENKO, A. D.: Slavjanskije literaturnyje mikrojazyki. Voprosy formirovanija i razvitija. Tallin: Valgus, 1981.

DULIČENKO, A. D.: Sovremennaja ètnojazykovaja mikroslavija: sostojanije i perspektivy razvitija. In: PLJIŠKOVA, A. (ed.): Rusyn’skỳj jazỳk medžì dvoma kongresamy. 
Zbornyk referatìv z III. Medžìnarodnoho kongresu rusyn'skoho jazỳka, Krakìv, 13.-16. 9. 2007. Prjašìv: Svìtovỳj kongres Rusynìv. İnštìtut rusyn'skoho jazỳka ì kulturỳ Prjašìskoj unìverzìtỳ v Prjašovì, 2008, S. 38-48.

DULIČENKO, A. D.: Sovremennoje jazykoznanije i slavjanskije literaturnyje mikrojazyki. In: DULIČENKO, A. D. - GUSTAVSSON, S. (eds): Slavjanskije literaturnyje mikrojazyki i jazykovyje kontakty: Materialy meždunarodnoj konferencii, organizovannoj v ramkach Komissii po jazykovym kontaktam pri Meždunarodnom Komitete slavistov. Tartu, 15-17 sentjabrja 2005 g. Slavica Tartuensia, VII. Tartu: Tartu Ülikooli Kirjastus, 2006, S. 22-46.

DULIČENKO, A. D.: Vvedenije v slavjanskuju filologiju. Učebnoje posobije. Moskva: Flinta-Nauka, 2016.

GAZETA WYBORCZA (22.12.2004): <http://wiadomosci.gazeta.pl/wiadomosci/1, 114873,2460850.html22.12.2004>. [online]. [cit. 2. 11. 2018].

GRAHL, S.: Werben fürs ,Sorbentum: Über den Versuch, eine Minderheitensprache zu revitalisieren. In: ELMENTALER, M. (ed.): Deutsch und seine Nachbarn. Kieler Forschungen zur Sprachwissenschaft, 1. Frankfurt am Main: Peter Lang Verlag, 2009, S. 47-60.

GUDASZEWSKI, G.: Rozdziat IV. Przynależność narodowo-etniczna, język i wyznanie. In: CHMIELEWSKI, M. (ed.): Ludność. Stan i struktura demograficzno-społeczna. Narodowy Spis Powszechny Ludności i Mieszkań 2011. Warszawa: Główny Urząd Statystyczny, 2013, S. 89-101.

HANNAN, K.: The Lachian Literary Language of Óndra Eysohorsky. The Slavic and East European Journal, 40, 4, 1996, S. 726-743.

HENTSCHEL, G.: Vorwort. In: HENTSCHEL, G. (ed.): Variation und Stabilität in Kontaktvarietäten. Beobachtungen zu gemischten Formen der Rede in Weißrussland, der Ukraine und Schlesien. Beiträge zu einem „Thematischen Block“ auf dem XV. Internationalen Slavistentag in Minsk, Weißrussland, August 2013. Studia Slavica Oldenburgensia, 21. Oldenburg: BIS-Verlag der Carl-von-Ossietzky-Universität, 2013, S. iii-v.

HENZELMANN, M.: Authentizität als treibende Kraft bei der Herausbildung slavischer Mikroliteratursprachen (am Beispiel des Pomakischen und des Schlesischen). Specimina Philologiae Slavicae, 185. München et al.: Verlag Otto Sagner, 2015.

HENZELMANN, M.: Das Schlesische als Sonderfall in der slavischen Mikrosprachenforschung. In: KUSSE, H. - SCHARLAJ, M. (ed.): Linguistische Beiträge zur Slavistik. XXIII. JungslavistInnen-Treffen in Dresden, 18.-20. September 2014. Specimina Philologiae Slavicae, 188. Leipzig: Biblion Media, 2016, S. 101-118.

KL'UD (Theatergruppe Kladzanske L'Udove Divadlo). <http://www.klud.cc/>. [online]. [cit. 2. 11. 2018].

LAMPRECHT, A.: K otázce lašských nářečí. Slovo a slovesnost, 16/3, 1955, S. 140-146. 
LEWASZKIEWICZ, T:: Obersorbisch. In: OKUKA, M. (ed.): Wieser Enzyklopädie des Europäischen Ostens, 10. Lexikon der Sprachen des Europäischen Ostens. Klagenfurt: Wieser, 2002, S. 343-354.

LEWASZKIEWICZ, T.: Dolnotużycki i górnotużycki - języki zagrożone czy wymierajace? Slavia Occidentalis, 2014, 71/1, S. 37-53.

LUBAŚ, W.: Kaschubisch. In: OKUKA, M. (ed.): Wieser Enzyklopädie des Europäischen Ostens, 10. Lexikon der Sprachen des Europäischen Ostens. Klagenfurt: Wieser, 2002, S. 265-273.

MARTI, R.: Haut- et bas-sorabe: une cohabitation linguistique difficile. Revue des études slaves, 2014, LXXXV-2, S. 215-233.

NIJAKOWSKI, L. M.: Die Politik des polnischen Staates gegenüber den nationalen und ethnischen Minderheiten. Polen-Analysen 2016, 177, S. 2-9.

NOWAK, M.: Sorben/Wenden und die Sprache Niedersorbisch - Ein Thema für den Deutschunterricht? In: BERNER, E. (ed.): Region-Sprache-Literatur. Unterrichtsanregungen und Materialien für den Deutschunterricht in der Primar- und Sekundarstufe. Potsdam: Universitätsverlag, 2017, S. 163-181.

RABUS, A.: Slavische Minderheitensprachen - Mikrostandardsprachen? Zeitschrift für Slavische Philologie, 2015, 71/1, S. 147-174.

RIPKA, I.: Na počiatku bola dialektológia... alebo Dialektika dejín discipliny. In: OLOŠTIAK, M. - IVANOVÁ, M. - SLANČOVÁ, D. (eds): Vidy jazyka a jazykovedy. Na počest Miloslavy Sokolovej. Acta Facultatis philosophicae universitatis Prešoviensis, Jazykovedný zborník, 34. Prešov: Filozofická fakulta Prešovskej univerzity v Prešove, 2011, S. 41-49.

RYKAŁA, A. - SOBCZYŃSKI, M.: Naród polski jako żywa struktura. Kszałtowanie się poczucia odrębności narodowej Ślazaków pod wptywem uwarunkowań geograficzno-historycznych i geograficzno-politycznych. In: RYKAŁA, A. (ed.): Mniejszości narodowe i etniczne w interpretacjach przestrzennych. Studia z Geografii Politycznej i Historicznej, 5. Łódź: Wydawnictwo Uniwersytetu Łódzkiego, 2016, S. 133-176.

SCHULZ, J.: Bilingualer Spracherwerb im Witaj-Projekt. Schriften des Sorbischen Instituts. Spisy Serbskeho instituta, 60. Bautzen-Budyšin: Domowina, 2015.

SPIESS, G.: Niedersorbisch. In: OKUKA, M. (ed.): Wieser Enzyklopädie des Europäischen Ostens, 10: Lexikon der Sprachen des Europäischen Ostens. Klagenfurt: Wieser, 2002, S. 323-342.

TAMBOR,J.: German Elements in the Silesian Ethnolect. In: KACZMARSKA, E. -NOMACHI, M. (eds): Slavic and German in Contact: Studies from Areal and Contrastive Linguistics. Slavic Eurasian Studies, 26. Sapporo: Hokkaido University Press, 2014, S. 135-164.

TÓBIK, Š.: Východoslovenské nárečia. (Úvod do ich d’alšieho výskumu a štúdia). Nové obzory, 1965, 7, S. 235-268. 
VERFASSUNG DES FREISTAATES SACHSEN: Dresden: Sächsischer Landtag, 2014. VERFASSUNG DES LANDES BRANDENBURG: <https://bravors.brandenburg.de/de/ gesetze-212792\#25>. [online]. [cit. 3. 11. 2018].

VICHODOSLOVENSKE ZDRUŽEŇE VALAL: <http://ilonas.net/valal/index.html>. [online]. [cit. 1. 11. 2018].

ZIENIUKOWA, J.: Kaszubszczyzna. In: GAJDA, S. (ed.): Język polski. Najnowsze dzieje języków słowiańskich. Opole: Uniwersytet Opolski - Instytut Filologii Polskiej, 2001, S. 477-491.

\section{About the author \\ Martin Henzelmann}

University of Hamburg, Faculty of Humanities, Department of Languages, Literature and Media II (SLM II), Institute of Slavic Studies, Hamburg, Germany

martin.henzelmann@uni-hamburg.de 